\title{
Trading technologies
}

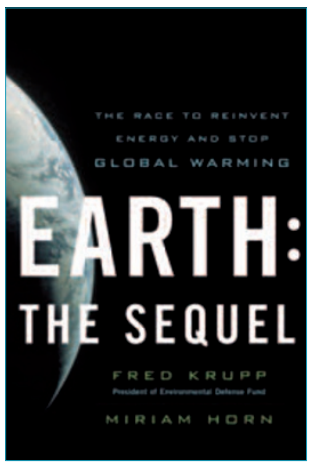

\section{EARTH: THE SEQUEL: THE RACE TO REINVENT ENERGY AND STOP GLOBAL WARMING}

\author{
by Fred Krupp and Miriam Horn
}

W. W. Norton: 2008. 256pp. US\$24.95

\section{Vast technological opportunities exist for providing the world with clean energy in the future, but the real debate is over the policies needed to decarbonize the growing global economy.}

Tradable emissions were first proposed as a solution to the problem of pollution by academics in the 1960s. But the idea failed to gain much standing in environmental policies at the time, and it wasn't until the 1970s that the United States began experimenting with small-scale emissions trading schemes. Their crowning success - and the world's first 'cap-andtrade' system - came in 1990, under the Clean Air Act Amendments designed to minimize acid rain. The scheme successfully reduced atmospheric sulphur dioxide by placing a cap, or legal limit, on emissions. Permits were allocated to emitters, and those who emitted less than their quota could trade the excess on a national market, thus making a profit while reducing pollution. This paved the way for similar programs in California and the northeast United States designed to limit pollutants such as nitrous oxides. Europe's foray into emissions trading finally came in 1997 with the Kyoto Protocol.

Fred Krupp, president of the Environmental Defense Fund (EDF) for the past 23 years, and journalist Miriam Horn propose in Earth: The Sequel that such a scheme, if adopted by the US for carbon dioxide emissions, would essentially do for global warming what reducing sulphur emissions did for acid rain, thus solving the challenge of climate change. Krupp, who played a key role in convincing the administration of George H. W. Bush to embrace the sulphur dioxide trading program, and Horn, who is also an EDF staffer, say it's "simple: the U.S. Congress must set a legal and steadily declining limit on global-warming pollution."

The basic tenet of their argument is that new technologies are urgently needed in the marketplace to meet the world's ever-increasing demand for energy without the accumulation of further carbon dioxide in the atmosphere. Hence the need for a carbon market with tradable credits to provide a profit incentive for low-carbon or carbon-free technologies - a motivation that could, in theory at least, energize a new breed of innovators.

But unfortunately, the book does not provide any argument for why a cap-and-trade approach would be more successful in reducing the concentration of atmospheric greenhouse gases than other proposed approaches, such as a carbon tax or direct subsidies for research, development, demonstration and deployment.

Instead, the authors simply assume that such a policy would succeed and focus their attention on an extended series of vignettes about scientists and engineers seeking to commercialize alternative energy technologies. These stories - which cover topics such as solar power, wave energy, geothermal and clean coal - offer interesting perspectives on practical scientific and technical applications just over the horizon. It is reassuring to know that there are vast technological opportunities for providing the world with clean energy in the future, and the strength of the book is its survey of this potential.

In placing their attention on the need for innovative energy technologies, however, Krupp and Horn have focused on the one area where advocates for action on greenhouse gas reduction are in strong agreement. They have avoided engaging in the real debate over the policies necessary to decarbonize the growing global economy and, crucially, over whether and how to put a price on carbon dioxide.

Ultimately, the authors argue that the virtue of a cap-and-trade approach is that it will raise the cost of carbon-intensive energy sources. Such cost increases are designed to cause economic discomfort and perhaps some degree of pain among energy consumers, which will be the necessity that mothers the invention and deployment of carbon-neutral energy technologies, revolutionizing our energy system. This chain of argument sounds wonderful, which is why it is the basis of recommendations found in august reports such as the Stern Review Report from the United Kingdom and those of the Intergovernmental Panel on Climate Change. A similar logic underpins calls for a carbon tax.

But the households and consumers who will pay the price of more expensive energy also happen to be citizens and often voters. Politicians who want to continue in their jobs spend every waking hour trying to avoid economic discomfort among their constituents, not cause it intentionally. Hence we see support for gas-tax holidays in the United States, continued subsidies of coal production and use in the United Kingdom and Germany, and steadfast refusal among the world's fastest-growing economies to even consider limits on emissions. Given the experiences unfolding around us, it seems fanciful at best to think that politicians are going to willingly increase the cost of energy by an amount sufficient to motivate their constituents.

Because Krupp and Horn don't engage in explaining why a cap-andtrade system would be the way forward, 
some of their assertions seem overstated, and a few are just wrong. For example, the authors compare the significance of the 2007 leveraged buy-out of the largest energy provider in Texas, which Krupp was involved in, with that of the global divestment in South Africa to protest apartheid, asserting that "the era of business as usual is over for coal." Yet coal plants are continuing to be built at a rapid pace in the United States and Europe, and especially in Asia.

The book's overwhelming focus on the United States is also frustrating, as many efforts to commercialize new energy technologies are going on around the world. Its suggestion that developing countries will enter into a binding global agreement to price carbon once the US signs up is little more than faith-based argumentation, as all available evidence points to the contrary. And Krupp and Horn do not explain how to overcome the problem that, without global participation in setting a price on carbon, partial efforts will merely displace and not reduce aggregate emissions.

Although Earth: The Sequel offers an interesting look at entrepreneurs in the energy technology business and may be of interest to those wondering who is working to commercialize alternative energy, it will be a disappointment to anyone seeking insight on why a cap-and-trade program makes sense and might succeed.

Published online: 29 May 2008

doi:10.1038/climate.2008.53

Roger A. Pielke, Jr

Roger A. Pielke, Jr is a Professor in the Environmental Studies Program at the University of Colorado.

e-mail:pielke@colorado.edu

\section{Siberian symbols}

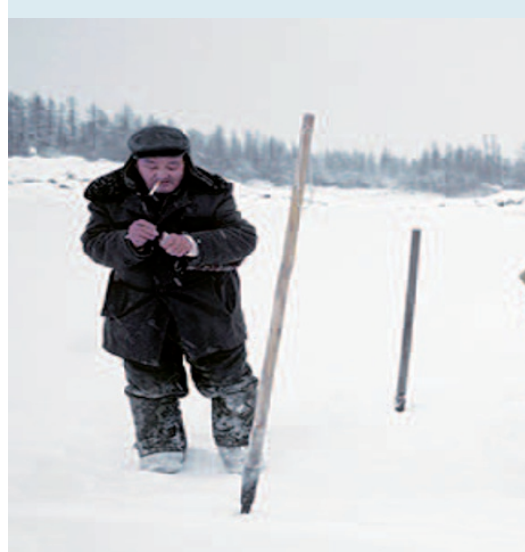

On the Kolyma river in the frigid northeast corner of Siberia, the few surviving communities of indigenous Yukaghir people live by elk hunting and ice fishing - and this traditional reliance on some of the Earth's coldest conditions makes their culture one of the world's most vulnerable to climate change. Warming in the Arctic, proceeding almost twice as fast as elsewhere on Earth, is expected to disrupt local freshwater fisheries whose relatively low value on the international market belies their crucial place in indigenous diets. Key Arctic fish species that spend all or part of their lives in Siberia's north-flowing rivers will have to contend with encroaching southern competitors and the possibility of new parasites as waters warm. The Yukaghir fishermen pictured here, from the village of Nelemnoye, are catching mostly broad whitefish (Coregonus nasus), one of the species most likely to be displaced.

Subhankar Banerjee's photographs of the Yukaghir and other indigenous Arctic people threatened by climate change are on display at the United Nations' New York headquarters 9-31 May. Banerjee is one of seven artists featured in the exhibition Unlearning Intolerance: Art, Attitudes \& Environment.

Published online: 29 May 2008

doi:10.1038/climate.2008.52

Anna Barnett 